\title{
Design and Test of Laser Transmission Welding System for Automotive Plastic Parts
}

\author{
Yu GU ${ }^{1, a}$, Ming HU ${ }^{1, b_{*}}$, Li-Jie ZHANG ${ }^{1, c}$ and Yu-Juan LIU ${ }^{2, d}$ \\ ${ }^{1}$ School of computer science \& engineering, Changchun University of technology, Changchuan \\ 130012, China; \\ ${ }^{2}$ College of Instrumentation and Electrical Engineering, Jilin University, Changchuan 130012 , \\ China;

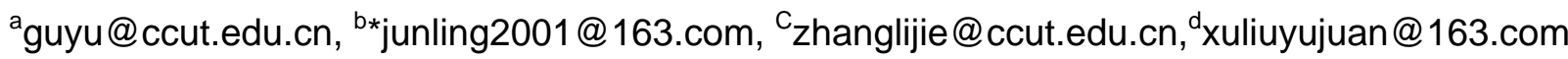 \\ ${ }^{*}$ Corresponding author
}

Keywords: Laser Transmission Welding, Plastic, Fiber, Automotive.

\begin{abstract}
With the development of the plastic connection technology and laser welding technology, as well as the improvement of the processing requirements of automotive plastic parts, laser transmission welding method is the first choice for the welding method of automobile plastic welding, which has the advantages of good welding quality, high efficiency and easy control. So the laser transmission welding is studied in this paper. The principle of laser transmission welding is introduced, and the transmission welding system of plastic laser is designed by using the optical fiber laser as the light source. The light beam collimation and focusing system is designed considering the divergence of the fiber laser source. The welding experiment of polypropylene specimen was carried out with the design of the optical fiber laser transmission welding system. Finally, the strength of welding specimen was tested. The results show that: the optical fiber laser transmission welding system in the laser power $40 \mathrm{~W}$, welding speed of $50 \mathrm{~mm} / \mathrm{s}$, carbon black content of $0.1 \%$, the welding strength is $379 \mathrm{~N}$, welding firm, meet the actual application needs.
\end{abstract}

\section{Introduction}

In recent years, with the development of science and technology and the improvement of manufacturing technology, the external appearance and beauty of the vehicle are becoming higher and higher, the mechanical connection method, adhesive bonding method and conventional welding method are difficult to meet the application requirements, especially in automotive plastic parts $[1,2,3]$. The plastic laser projection welding method which originated in 1970 has the advantages of precision, firm, seal, welding speed, easy operation, no contact and no pollution. It can effectively compensate for the shortcomings of traditional welding method, and become one of the development of high quality plastic welding method $[4,5,6,7]$. The principle of the plastic laser projection welding method and its application in automobile parts welding has been studied in Toyota Corporation, Leister Corporation, etc., also has been put into large-scale industrial production $[8,9,10]$.

But scholars began to study the laser projection welding method in China is relatively late. In 2003, Huazhong University of Science and Technology began to study the laser welding of plastic chip [11], and then the National University of Taiwan, Dalian University of Technology, Jiangsu University, etc., have also carried out the research of laser welding [12-18]. There is no relevant report on the method of laser projection welding of automobile plastic parts in China.

Therefore, in this paper, a semiconductor laser transmission welding optical system for plastic welding was designed, and the experiment of the welding experiment and the strength test were carried out. 


\section{Principle of Laser Transmission Welding}

Plastic laser transmission welding method can realize the connection of two plastic components using laser technology. The principle is shown in Fig. 1. Component 1 and component 2 are the components to be connected, and absorbent is added to the contact surface between this two components. The beam emitted from laser passes through component 1 and absorbent, then arrives at the upper surface of component 2. Component 2 absorbs laser energy and the energy is converted into heat energy by the absorbent.

The heat energy causes the material to melt at the two contact surface. The two components are fused together under the clamping force of the external fixture, after cooling weld line was formed.

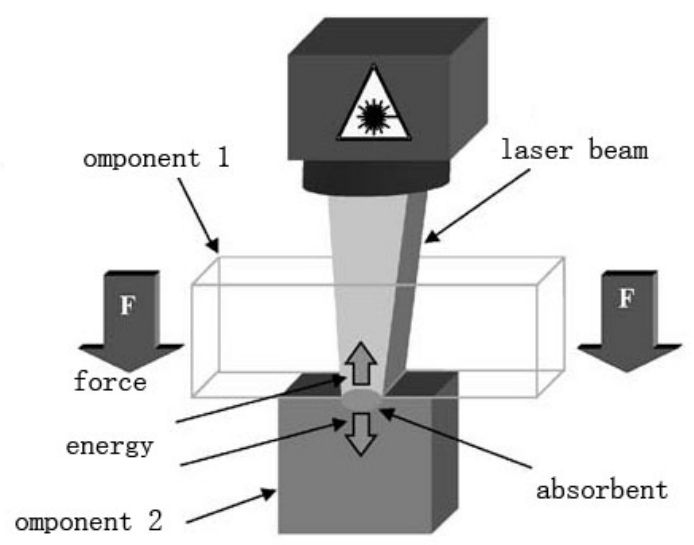

Fig. 1 Principle of laser transmission welding of plastics

In order to realize the high quality connection of two plastic components, the two connecting components must meet the following requirements. Firstly, the connecting component 2 and component 1 must be thermoplastic material. Secondly, component 1 has a high transmittance at the wavelength of the laser beam, and the connecting component 2 has a high absorption rate at the wavelength of the laser beam.

\section{Design of Optical System for Semiconductor Laser Transmission Welding}

Laser source is the key part of laser transmission welding system, its wavelength, aperture, laser power and the effect of plastic penetration depth directly influence the weld quality of plastic welding. Semiconductor laser has the advantages of good beam quality, high conversion efficiency, low cost, easy to realize miniaturization, power fully meet the requirements of the system. Therefore, the semiconductor laser was chose as the light source of the laser transmission welding system. The parameters of the laser are shown in Table 1.

Table 1 Parameters of laser

\begin{tabular}{ll}
\hline Parameters & value \\
\hline Wavelength $[\mu \mathrm{m}]$ & 0.976 \\
\hline Maximum power[W] & 100 \\
\hline Fiber core diameter [mm] & 0.4 \\
\hline Fiber numerical aperture [mm] & 0.22 \\
\hline
\end{tabular}






Fig. 2 FC-W-980H laser

Laser beam is a divergent beam. However laser transmission welding beam of the laser transmission welding system must be a collimation beam. Therefore, it is necessary to design a laser beam collimation optical system. According to the parameters of the laser in table 1, the fiber core diameter is $0.4 \mathrm{~mm}$, the diameter of the collimation optical system is also $0.4 \mathrm{~mm}$, and the numerical aperture of the collimation optical system is 0.22 .According to the theory of paraxial ray propagation [19]. The focal length of the collimation optical system is $120 \mathrm{~mm}$, its optical transmittance is higher than $95 \%$, its spot diameter is $0.4 \mathrm{~mm}$. Platform of the laser projection welding system as shown in figure 3.

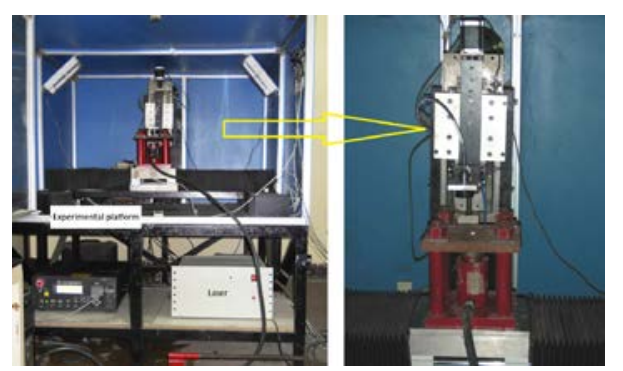

Fig. 3 Experimental platform of laser transmission welding system

\section{Example and Results}

Welding experiment of the polypropylene specimen was carried out by using the laser transmission welding system as shown in Figure 3. The laser power was $40 \mathrm{~W}$, the welding speed was $50 \mathrm{~mm} / \mathrm{s}$, the carbon black was chosen as the absorbent, and the carbon black content was $0.1 \%$. After welding, the microscopic amplification 110 times image of weld seam is as shown in Figure 4.

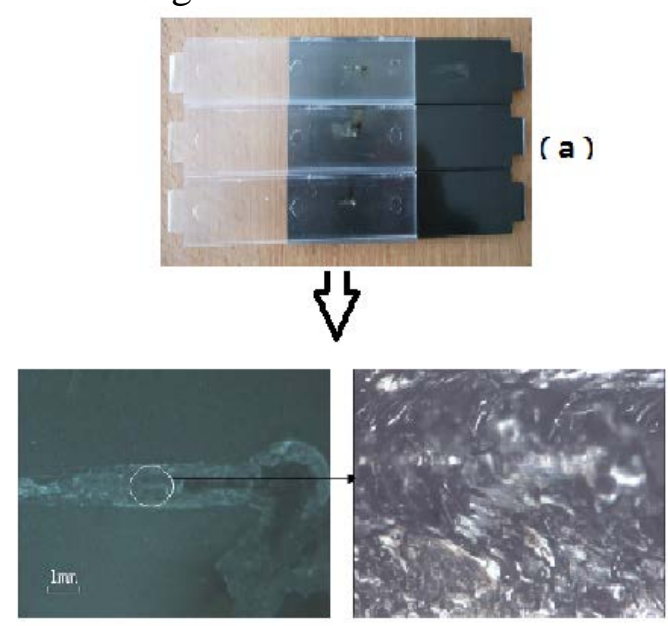

(b)

Fig.4 Amplification 110 times image of weld seam 
As can be seen in Fig. 4, the weld seam edge was clear and deep. Strength test of welding specimen was carried out. The overflow of carbon black in the weld seam was less. The welding experiment result was ideal. The result has shown that when the laser power was $40 \mathrm{~W}$, welding speed was $50 \mathrm{~mm} / \mathrm{s}$, carbon black content was $0.1 \%$, the strength was $379 \mathrm{~N}$.

\section{Conclusions}

Laser transmission welding method has the advantages of good welding quality, high efficiency and easy control. A laser transmission welding system has been designed with Semiconductor laser. This system has been used for welding test specimen; finally the strength test of weld has been carried out. This welding was firm and meets the needs of the practical application.

\section{Acknowledgement}

This research was financially supported by the Jilin Province, Industrial Technology Research and Development Project.

\section{References}

[1] LUAN H, Plastic two processing. Beijing,China Light Industry Press, 1999.

[2] LIU H X. The method and development of laser welding plastics, Laser Technology, 32(2008) $166 \sim 170$.

[3] WANG J CH, Development and expectation of laser welding technology. Laser Technology, 25(2000) 48 53.

[4] WANG J CH,QIN L M,LI J. Technics and Microcosmic Analysis Research of PMMA/ABS Thermoplastic Laser Transmission Welding. APPLIED LASER. 4 (2008) 287 291.

[5] Troughton M, Handbook of plastics joining. Norwich, William Andrew Publishing, 1997 .

[6] Churchill SW, Clark GC, Sliepcevich CM. Light-scattering by very dense monodispersions of latex particles. Discuss Faraday Soc30: (1960) 192-199.

[7] SHEN X X, WANG CH Y. Development on methods of laser welding of plastics. The International Conference on Electrical and Control Engineering(ICECE).China:2010.

[8] WANG Y Y, Application of semiconductor laser in plastic parts of welding automobile,Laser Technology \& Applications, 1(2006) 27 30.

[9] Toyota Jidosha, K.K., Laser beam welding of plastic plates. Patent Application JP85213304.26 (1985).

[10] Haberstroh, E. et al., Laser transmission joining in microtechnology. Microsystem technologies, 12(2006) 632-639.

[11] Potente, H. and G. Fiegler, Using models to describe the joining process. Kunststoffe Plast Europe , 94(2004)53-56.

[12]CHEN X Q, Study on laser welding packaging system of plastic chip, Micronanoelectronic technology, 40(2003) 254-256.

[13] LAI J J,Infrared laser heating bonding of microchip. infrared technology, 26(2004) 68-76.

[14]Wang, S., A Novel Scheme of LPOF by Jointing an Aspheric Plastic Lens and a Plastic Fiber Using Laser Transmission Welding. 2005.

[15] WANG Y L, Laser welding process of micro plastics. Application laser,26(2006) 93-96. 
[16]XIE L,LIU L M. Laser welding technology and properties of polymer materials plastics. Journal of welding, 28(2007)97-100.

[17]LIU H X , Temperature Field Simulation on Laser Transmission Welding of Polyvinylchloride ,CHINESE JOURNAL OF LASERS, ,35(2008) 1801-1807.

[18]LI J, MECHANISM AND TECHNICS RESEARCH OF PMMA/ABS THERMOPLASTIC LASER TRANSMISSION WELDING. Shanghai Jiao Tong University: (2008).

[19] YUN D Y, Engineering Optics,China machine press, Beijing(2007) 